\title{
Laparoscopic Surgery in the Elderly: A Review of the Literature
}

\author{
Andrew T. Bates and Celia Divino*
}

Mount Sinai Medical Center, New York, NY 10029, USA

[Received February 6, 2014; Revised April 25, 2014; Accepted April 29, 2014]

\begin{abstract}
Laparoscopic techniques are gradually replacing many common surgical procedures that are performed in an increasingly aging population. Laparoscopy places different physiologic demands on the body than in open surgery. PubMed was searched for evidence related to the use of laparoscopy in the elderly population to treat common surgical pathologies. Randomized trials, systematic reviews, and metaanalyses were preferred. Currently, over $40 \%$ of all surgeries performed in the U.S. are on patients older than 65 years. By the end of the 21st century, Americans are expected to live 20 years longer than the current average. However, elderly patients clearly show higher rates of surgical morbidity and mortality overall. Laparoscopic techniques show decreased wound complications, post-operative ileus, intraoperative blood loss, and reduced need for post-operative rehabilitation. In conclusion, laparoscopic surgery is safe in the elderly population and affords multiple advantages including decreased pain and convalescence. However, the physiology of laparoscopy places demands on elderly patients that typically present with more medical comorbidities.
\end{abstract}

Key words: Laparoscopy, Elderly, Surgery, Geriatric

The general trend in general surgery for the past 25 years has been the shift toward minimally-invasive alternatives from conventional operations. Elderly patients represent a large cohort of surgical patients, and are therefore profoundly affected by this shift in care. Where feasible, laparoscopic surgery is becoming the gold standard in the treatment of many common pathologies that disproportionately affect elderly patients. The benefits of laparoscopy have been well documented, including decreased post-operative pain, decreased hospital length of stay, improved cosmesis, and a quicker return to normal activity. On the contrary, laparoscopy may be more technically challenging, owing to a significant learning curve among surgeons, and carries with it a distinct milieu of physiologic demands on the elderly patient.

As the American population ages, a greater proportion of surgical patients are above 65 years of age than ever before. Surgeons are now confronted with a patient population that is older, has a decreased cardiopulmonary reserve, and carries a longer list of medical comorbidities and prior surgical history. Likewise, primary care providers are caring for a population that is increasingly more likely to need or to have undergone a surgical procedure. It is therefore imperative that both PCPs and general surgeons are comfortable with the management of elderly patients with surgical pathologies. This paper will review the physiology of basic laparoscopy, as well as the current surgical literature of four common laparoscopic surgeries that are increasingly common in elderly patients.

\section{Demographics}

The average surgical patient in most western countries is becoming older. The populations of the United States and Western Europe are steadily aging, due in part to the

*Correspondence should be addressed to: Celia Divino, MD. Mount Sinai Medical Center, New York, NY, USA. 
"Baby Boomer" generation as well as increasing overall life expectancy $[1,2]$. Projections from the U.S. Census Bureau predict an increase in the proportion of Americans greater than 65 years of age from $12.8 \%$ in 1995 to $15 \%$ in 2020 [1]. This trend is similar in Europe as well [2]. Furthermore, Americans are living longer, with a yearly increase in life expectancy by 2-3 months. By the end of the 21 st century, Americans are projected to live 20 years longer than the current average. Currently, the patients older than 65 years represent over $40 \%$ of all surgeries performed [3]. This figure is expected to increase substantially over the coming decades, with a complementary increase in surgical demand.

In general, the morbidity and mortality of surgical patients increases with age. A study of VA patients utilizing the National Surgical Quality Improvement Project (NSQIP) database showed higher thirty-day allcause mortality in elderly patients undergoing various surgical procedures ( $8 \%$ in elderly patients versus $3 \%$ in non-elderly patients), although the mortality rates remained less than $2 \%$ for most common operations such as transurethral prostatectomy, hernia repair, and knee replacement [3]. When limited to laparoscopic procedures, the outcomes in elderly patients is superior. A prospective study from Spain showed the outcomes of patients older than 70 years undergoing various common laparoscopic procedures, with morbidity at $10.8 \%$ and $30-$ day mortality at $3.4 \%$ [4]. Both figures were lower than previously reported rates of open procedures in the literature.

\section{Physiology of Laparoscopy}

The surgical requirements for laparoscopic surgery place unique physiological demands on the patient and present a distinct challenge in the elderly patient. The insufflation of carbon dioxide gas can create acid-base disturbances, changes in blood gas balance, and alterations of cardiovascular and pulmonary physiology [5]. While most of these changes do not result in clinical significance, they can become more of a factor in patients with comorbid conditions, especially those that result in decreased cardiopulmonary reserve, as are common in elderly patients.

Insufflation of the abdomen with gas places stress on the body's normal homeostatic mechanisms. Specifically, pneumoperitoneum with carbon dioxide can result in elevated arterial pCO2 levels and cause acid-base disturbances [5]. Ivankovich et al. found higher $\mathrm{pCO} 2$ levels in patients when $\mathrm{CO} 2$ insufflation was used than when $\mathrm{N} 2 \mathrm{O}$ gas was used [6]. In studies of patients undergoing laparoscopy under local anesthesia, the patients responded to intraperitoneal $\mathrm{CO} 2$ with hyperventilation [7]. Additionally, in patients who were insufflated with intraperitoneal $\mathrm{CO} 2$, researchers observed a rise in end-tidal CO2 [8]. Subsequent studies in porcine models demonstrated no associated rise in $\mathrm{O} 2$ consumption, indicating that absorbed $\mathrm{CO} 2$ insufflation was the cause of hypercarbia. In patients with severe cardiopulmonary disease, this hypercarbia can be exacerbated, leading to significant acidosis [5.8.10].

The physical stresses of abdominal insufflation can also produce changes in pulmonary mechanics. With achievement of pneumoperitoneum, diaphragmatic excursion is limited and the patient may show a rise in peak airway pressures, as well as a decline in pulmonary compliance and vital capacity [5]. Intra-abdominal pressure may also transfer across the diaphragm into the thoracic cavity, which can worsen gastroesophageal reflux and aspiration risk in susceptible patients. Furthermore, this transfer can be worsened by Trendelenberg (head-down) positioning during surgery [10].

Intra-abdominal pressure produces alterations in hemodynamic function that may alter cardiac function and the perfusion of vital organs. With increasing intraabdominal pressure, there is an associated decrease in venous return to the heart and resulting tachycardia [5]. This physiologic compensation initially produces a rise in caval pressures. In addition, systemic vascular resistence (SVR) and mean arterial pressure (MAP) rises. An intraabdominal pressure of $15 \mathrm{mmHg}$ has been shown to produce adequate visualization with manageable alterations in hemodynamic function. The increased pressure on intra-abdominal organs has been shown to decrease vascular perfusion, which has been shown to decrease renal and hepatic function $[9,12]$. In the case of laparoscopic cholecystectomy, with increased liver compression during retraction, this effect is magnified and should be considered in patients with underlying liver dysfunction [12].

In elderly patients undergoing general surgical procedures, the physiologic demands of laparoscopy should be considered before recommending surgical treatment. Although laparoscopy is minimally invasive in its dissection techniques, the increased physiologic demands discussed above present particular challenges among elderly patients.

\section{Common Procedures}

Due to the prevalence of surgical disease in the elderly, many primary care physicians are likely to care for patients that have undergone common general surgery procedures. Here, we present recent literature concerning 
four common surgical procedures that disproportionately affect elderly patients.

\section{Laparoscopic Cholecystectomy}

Currently, 95\% of cholecystectomies in the United States are performed using the laparoscopic technique [13]. This shift represents one of the fastest and most dramatic transformations in medical and surgical treatment of the last few decades. An open cholecystectomy requires a right subcostal incision of at least $20 \mathrm{~cm}$ in length, which produces significant post-operative disability caused by the division of the rectus muscle. A cholecystectomy performed via the standard laparoscopic technique requires a periumbilical trocar for the camera and two to three 5-mm trocars in the right abdomen for working. Those patients who undergo laparoscopic cholecystectomy for elective indications typically return to home the same day, while those patients who are admitted with acute biliary pathology often return home on the first post-operative day.

Gallstone disease disproportionately affects elderly patients. Population studies have demonstrated a prevalence of $9.3 \%$ in the general population [14]. When stratified for age, the prevalence was $2.4 \%$ in individuals of $20-29$ years of age, and $27.5 \%$ in persons of more than 70 years of age. As the population increases in age, the average age of presentation with gallbladder pathology is also expected to rise [14].

Older patients are more likely to experience complications following laparoscopic cholecystectomy $[15,16,17]$. The overall rates of morbidity and mortality remain less with the laparoscopic technique versus open. The reported incidence of morbidity and mortality in elderly patients undergoing open cholecystectomy is about $25 \%$ and $2 \%$, respectively. With laparoscopic cholecystectomy, these figures are lowered to $10 \%$ and $1 \%$, respectively [16]. Elderly patients typically have a longer length of stay, postoperatively, and usually have a higher ASA classification preoperatively [18]. The elderly population is more likely to require conversion from laparoscopic to an open cholecystectomy. This is the result of, on average, a longer history of gallbladder pathology, chronicity of disease, as well as an oftendelayed presentation to the hospital in the acute setting $[15,16,17]$.

\section{Laparoscopic Inguinal Hernia Repair}

Inguinal hernia remains one of the most common pathologies addressed by the general surgeon. Based on a recent review in Britain, the lifetime incidence is $27 \%$ for men and 3\% for women [19]. Although the recommendation was previously to repair detectable hernias, recent recommendations, notably from European surgical societies, have advocated for conservative therapy in minimally symptomatic hernias. This is due to a risk of incarceration of less than $0.2 \%$ per year, and a $10-12 \%$ risk of postoperative pain syndromes [19]. However, pain and incarceration remain indications for surgical repair [19].

Inguinal hernia repair remains a divided issue among general surgeons with no significant difference in the quality of repair between open and laparoscopic approaches [20,21]. The open procedure involves a single inguinal incision, usually extending about $10 \mathrm{~cm}$ in length, and a tension-free "plug and patch" method of herniorraphy [20]. The laparoscopic approach can be either transabdominal (TAP) or extraperitoneal (TEP). The TEP approach, the more common of the two, uses three laparoscopic incisions in the lower midline in the abdomen, and places a piece of mesh into the defect without entering the peritoneal cavity. The benefits of the laparoscopic approach include improved decreased postoperative pain, decreased risk of chronic pain, and a faster return to work and daily activities [20,21]. However, the initial enthusiasm for the laparoscopic approach has been replaced by a more judicious utilization of the technique, which has been shown to be preferable in recurrent and bilateral inguinal hernias. This trend is the result, in part, to multiple factors including increased cost and a relatively long learning curve [21].

The efficacy of open and laparoscopic repair is dependent on the experience of the surgeon. The rate of hernia recurrence after suture (Shouldice) repair is about $10 \%[20,21]$. The placement of mesh (Lichtenstein) for a "tension-free" repair decreases this risk to about $1 \%$ [21]. In comparison, the rates of recurrence are similar in laparoscopic repair and open mesh repair. However, the recurrence rates are higher in laparoscopic cases if performed by a less experienced surgeon [21].

The risk of post-herniorraphy inguinodynia is of particular importance in elderly patients, who are often limited functionally at baseline and for whom chronic pain may have even more deleterious effects on quality of life [22]. A prospective series of open mesh repairs (Lichtenstein) noted that $19 \%$ of patients had chronic pain at their 1-year follow-up visit. Of note, $6 \%$ of patients had moderate to severe pain [23]. A population-based study from Scotland recently showed that post-operative inguinodynia was associated with younger age and female gender [24]. Previously, laparoscopic repair was thought to have decreased rates of chronic pain compared to open mesh repair. Randomized long-term studies previously showed equal rates of inguinodynia at 2 years, 5 years, and equal rates of pain clinic follow-up. However, larger 
and more recent studies showed rates of chronic pain of $10 \%$ and $20 \%$ in the laparoscopic (TEP) and open repair groups, respectively [25]. Predictors of chronic pain included increased BMI, longer recovery times, and significant difference between pre-operative and postoperative physical testing [25]. The pain from inguinodynia often resolves with time but may require treatment including anti-inflammatories, nerve blocks, and neurectomy.

The largest review to date comparing open and laparoscopic repair showed increased complications with laparoscopic repair, although improved outcomes overall [26]. Utilizing the Cochrane database, McCormack et al (2003) showed low complication rates for both procedures, although more common in the laparoscopic cases for both visceral $(8 / 2315$ vs. $1 / 2599)$ and vascular (7/2498 vs. 5/2758) injuries [26]. The review confirmed previous findings of decreased time back to work, and decreased rates of chronic pain with the laparoscopic group. The efficacy of hernia repair between the two groups is equivalent.

In the elderly population, a shorter period of recovery and physical inactivity is more significant than in younger populations. While no studies have specifically examined the differences of open and laparoscopic repair in the elderly population, it can be inferred that elderly patients can benefit from the laparoscopic approach in the hands of an experienced surgeon.

\section{Laparoscopic Ventral Hernia Repair}

A ventral hernia is any hernia located on the anterior abdominal wall, comprising umbilical and incisional hernias, among rarer defects. While small $(<2 \mathrm{~cm})$ umbilical hernias may be repaired primarily with no mesh, the use of synthetic mesh has greatly improved recurrence rates, especially in larger fascial defects [28]. This improvement is especially important in the elderly population, for which problems of tissue healing with decreased connective tissue become an issue.

The operative approach typically involves the placement of working laparoscopic trocars lateral to the fascial defect $[27,28,29]$. Depending on surgeon preference, a combination of laparoscopic tacks and sutures are used to secure the mesh over the hernia defect. It is the fixation of the mesh that produces the largest contribution to postoperative pain, and current ongoing studies are examining the use of regional nerve blocks to improve mobility, analgesia usage, and respiratory function post-operatively [28].

Compared to open ventral hernia repair, multiple studies have shown conflicting data on laparoscopic outcomes. Based on a recent long-term follow-up study, laparoscopic repair was shown to have a significant decrease in patient morbidity while having no significant change in the rate of hernia recurrence [27]. However, a more recent randomized trial showed perioperative complications to be significantly higher $(9 \%$ vs. $2 \%$, $\mathrm{p}=0.02$ ) in laparoscopic cases versus open repair [28]. Additionally, laparoscopic repair required longer operative times. The same trial did show no significant difference in hernia recurrence rates, however. A metaanalysis using the Cochrane Database concluded the recurrence rates between open and laparoscopic repair to be equivalent [29]. The study, while confirming the slightly higher risk of perioperative complication with laparoscopic surgery, determined the difference to be due to increased risk of enterotomy during complex lysis of intraabdominal adhesions. The laparoscopic group showed significantly lower rates of wound infection, shorter length of hospital stay, as well as shorter time to regular activity at home [29]. This shorter length of physical debilitation is especially significant for elderly patients, many of whom have decreased physicality and functionality at baseline.

\section{Laparoscopic Colon Resection}

Based on the most recent national data, men and women born today have slightly less than $5 \%$ chance of developing colon cancer in their lifetime. It is estimated that 140,000 new cases of colorectal cancer are diagnosed annually, and 50,000 patients die form the disease each year [30]. About $61 \%$ of newly diagnosed colon cancers occurred in patients greater than 65 years of age. Prevalence rates were higher among men $(54: 100,000)$ than women $(40: 100,000)[30]$. The prevalence of colon cancer remains higher in Western countries, presumably due to dietary differences.

Laparoscopic colon resection has added a new treatment modality for patients with colon cancer, ulcerative colitis, and Crohn's Disease [31-36]. In the case of colorectal cancer, the adoption of laparoscopic techniques has been slower, owing to more novel technologies, slower development of necessary laparoscopic skills, and a perceived difficulty of colonic resection [36]. In the case of colon carcinoma, the degree of resection is determined by the location and extent of the primary tumor. For example, a tumor located in the cecum or ascending colon will require a resection of the entire right colon, including its mesentery to ensure an adequate lymph node resection.

Recent studies have shown oncologic equivalence between laparoscopic resection and open procedures. One 5-year prospective study from the 1990s showed equivalence with respect to resection margin and nodal 
dissection [31]. Multiple series from the same period showed equivalence between open and laparoscopic resection for each oncologic stage of colon carcinoma [32]. Although initial case reports raised concern of increased incidence of cancer recurrence within laparoscopic port or extraction sites [34], this fear is unsubstantiated in the literature. A retrospective review showed the wound recurrence rate to be $1.1 \%$, which is comparable to previous documented recurrence rates from open resection ( $1 \%$ and $1.5 \%)$. Additionally, the prospective, NIH-funded COST Trial confirmed equivalence between open and laparoscopic resection and the rates of wound recurrence [35].

Open resection carries the morbidity associated with a large midline laparotomy incision, in contrast to the relatively small incisions of laparoscopic resection. Open resection has been shown to require increased length of stay. In one prospective study, open resection required, on average, 4 additional days of inpatient admission (9.7 vs. 5.7 days) when compared to laparoscopic resection [35]. The same series also showed increased wound problems, longer postoperative ileus, and greater blood loss in open resection. Retrospective series have not only shown decreased post-operative complications in the laparoscopic group, but this difference becomes more pronounced when analysis is limited to patients older than 70 years [35]. The decrease in functionality associated with midline laparotomy also confers an increased use of subacute rehabilitation centers as an intermediate stage between the hospital and home. One recent retrospective analysis demonstrated that open compared to laparoscopic technique was independently associated with increased chance of discharge to a skilled facility (OR 2.85) [37]. The same series also showed that $33.3 \%$ of all colon resections required discharge to skilled facilities. Additional studies are needed to determine if the increased system cost of laparoscopic colon resection is outweighed by the increased hospital stay and postdischarge rehabilitation needs of open resection.

\section{Future Directions}

While laparoscopic surgery represents a massive shift in surgical technique towards less invasive procedures, a push continues in the field toward techniques that may possibly carry decreased morbidity. Single-incision laparoscopic surgery (SILS), natural orifice translumenal endoscopic surgery (NOTES), and robotic surgery are all attractive advances that bring advantages as well as novel challenges to surgical treatment. Robotic surgery, in particular, builds upon the advances of laparoscopic surgery and helps minimize its limitations [38]. Specifically, robotic instruments are flexible, offering an advantage over rigid laparoscopic instruments, especially in confined areas such as the pelvis. As technology progresses, the ease with which surgeons perform difficult dissections will increase, hopefully leading to improved outcomes. The novel approaches remain at this time more costly than traditional laparoscopy, which has limited implementation thus far.

\section{Summary}

The population of Western Europe and the United States is quickly becoming proportionally older with everincreasing life spans, with a parallel increase the number of elderly patients undergoing typical general surgery procedures. Laparoscopic surgery confers several benefits, including decreased postoperative pain, shorter length of hospital stay, and a more rapid return to regular daily activities. In this way, laparoscopic surgery is wellsuited to respond to the challenges of an elderly population. However, the specific physiological demands of laparoscopic surgery requires a thorough understanding of surgical technique and the particular comorbidities by which many elderly patients suffer.

\section{References}

[1] U.S. Government Printing Office. U.S. Bureau of the Census Current Population Reports, series P-25, N. 952, projections of the population of the United States by age, sex, and race: 1983-2080 (2000). Washington, DC: U.S. Government Printing Office.

[2] Münz R (2007). Old Europe. A look ahead the twentyfirst century. Eurozine, 4(25):1-10.

[3] Turrentine FE, Hongkun W, Simpson VB, Jones RS (2006). Surgical Risk Factors, Morbidity, and Mortality in Elderly Patients. JACS, 203(6):865-877.

[4] Ballesta Lopez C, Cid JA, Poves I, Bettonica C, Villegas L, Memon MA (2003). Laparoscopic surgery in the elderly patient. Surg Endosc, 17(2):333-7.

[5] Safran DB, Orlando R (1994). Physiologic effects of Pneumoperitoneum. 3rd Am J Surg, 167(2): 281-6.

[6] Ivankovich AD, Miletich DJ, Albrecht RF, Heyman HJ, Bonnet RF (1975). Cardiovascular effects of intraperitoneal insufflation with carbon dioxide and nitrous oxide in the dog. Anesthesiology, 42:281-7.

[7] Brown DR, Fishburne JI, Roberson VO, Hulka JF (1976). Ventilatory and blood gas changes during laparoscopy with local anesthesia. Am J Obstet Gynecol, 124:741-5.

[8] Ho HS, Gunther RA, Wolfe BM (1992). Intraperitoneal carbon dioxide insufflation and cardiopulmonary functions. Arch Surg, 127:928-32.

[9] Demyttenacre SV. Feldman I.S., Bergman S (2006). Does aggressive hydration reverse the effects of pneumoperitoneum on renal perfusion? Surg Endosc, 20: $274-80$. 
[10] O’Malley C, Cunningham AJ (2001). Physiologic changes during laparoscopy. Anesthesiol Clin North America. 19:1-19.

[11] Milheiro A, Castro Sousa F, Oliveira L, Joao Matos M (1996). Pulmonary function after laparoscopic cholecystectomy in the elderly. Br J Surg, 83:10591061.

[12] Demyttenaere S, Feldman LS, Fried GM (2007). Effect of pneumoperitoneum on renal perfusion and function: a systematic review. Surg Endosc, 21(2):152-60.

[13] Orlando R III, Russell JC, Lynch J, Mattie A (1993). Laparoscopic cholecystectomy: a statewide experience. Arch Surg, 128: 494-9.

[14] Coelho JC, Bonilha R, Pitaki SA, Cordeiro RM, Salvalaggio PR, Bonin EA, Hahn CG, Soares RV, Milcheski DA (1999). Prevalence of gallstones in a Brazilian population. Int Surg, 84(1):25-8.

[15] Magnuson TH, Ratner LE, Zenilman ME, Bender JS (1997). Laparoscopic Cholecystectomy: applicability in the geriatric population. Am Surg. 63(1):91-6.

[16] Annamaneni RK, Moraitis D, Cayten CG (2005). Laparoscopic cholecystectomy in the elderly. JSLS, 9(4):408-10.

[17] Mayol J, Marttinez-Sarmiento J, Tamayo FJ, Alvarez Fernandez-Represa J (1997). Complications of laparoscopic cholecystectomy in the ageing patient. Age Ageing, 26:77-81.

[18] Massie MT, Massie LB, Marrangoni AG, D'Amico FJ, Sell, Jr. HW (2009). Advantages of Laparoscopic Cholecystectomy in the Elderly and in Patients With High ASA Classifications. J Laparoendosc Surg, 3(5): 467-476.

[19] John T Jenkins, Patrick J O’Dwyer (2008). "Inguinal hernias". BMJ, 336(7638): 269-272.

[20] Dallas, K. B., Froylich, D., Choi, J. J., Rosa, J. H., Lo, C., Colon, M. J., Telem, D. A. and Divino, CM (2013). Laparoscopic versus open inguinal hernia repair in octogenarians: A follow-up study. Geriatrics \& Gerontology International, 13: 329-333.

[21] Hope WW, Bools L, Menon A, Scott CM 3rd, Adams A, Hooks WB 3rd (2012). Comparing laparoscopic and open inguinal hernia repair in octogenarians. Hernia, Nov 7. [Epub ahead of print]

[22] Aasvang E, Kehlet H (2005). "Chronic postoperative pain: the case of inguinal herniorrhaphy". Br J Anaesth, 95(1):69-76.

[23] Callesen T, Bech K, Kehlet H (1999). Prospective study of chronic pain after groin hernia repair. $\mathrm{Br} \mathrm{J}$ Surg, 86(12):1528-31.

[24] Courtney CA, Duffy K, Serpell MG, O'Dwyer PJ (2002). Outcome of patients with severe chronic pain following repair of groin hernia. Br J Surg, 89(10):1310-4.

[25] Grant AM, Scott NW, O'Dwyer PJ, MRC Laparoscopic Groin Hernia Trial Group (2004). Five-year follow-up of a randomized trial to assess pain and numbness after laparoscopic or open repair of groin hernia. $\mathrm{Br} \mathrm{J}$ Surg, 91(12):1570-4.

[26] McCormack K, Scott NW, Go PM, Ross S, Grant AM, EU Hernia Trialists Collaboration (2003). Laparoscopic techniques versus open techniques for inguinal hernia repair. Cochrane Database Syst Rev. (1):CD001785.

[27] Bingener J, Buck L, Richards M, Michalek J, Schwesinger W, Sirinek K (2007). Long term Outcomes in Laparoscopic vs Open Ventral Hernia Repair. Arch Surg, 142(6):562-7.

[28] Nguyen SQ, Divino CM, Buch KE, Schnur J, Weber KJ, Katz LB, Reiner MA, Aldoroty RA, Herron DM (2008). Postoperative pain after laparoscopic ventral hernia repair: a prospective comparison of sutures versus tacks. JSLS, 12(2):113-6.

[29] Sauerland S, Walgenbach M, Habermalz B, Seller CM, Miserez M (2011). Laparoscopic versus open surgical techniques for ventral or incisional hernia repair. Cochrane Database Syst Rev, 16(3):CD007781.

[30] Howlader N, Noone AM, Krapcho M, et al (2009). SEER Cancer Statistics Review, 1975-2009 (Vintage 2009 Populations). National Cancer Institute. Bethesda, MD.

[31] Franklin ME Jr, Rosenthal D, Abrego-Medina D, Dorman JP, Glass JL, Norem R, Diaz A (1996). Prospective comparison of open vs. laparoscopic colon surgery for carcinoma: five-year results. Dis Colon Rectum, 39:S35-S46.

[32] Lujan HJ, Plasencia G, Jacobs M, Viamonte M III, Hartmann RF (2002). Long-term survival after laparoscopic colon resection for cancer: complete fiveyear follow-up. Dis Colon Rectum, 45:491-501.

[33] Allardyce RA, Bagshaw PF, Frampton CM, Frizelle FA, Hewett PJ, Rieger NA, Smith JS, Solomon MJ, Stevenson ARL (2010). Australasian Laparoscopic Colon Cancer Study shows that elderly patients may benefit from lower postoperative complication rates following laparoscopic versus open resection. Br J Surg, 97:86-91.

[34] Wexner SD, Cohen SM (1995). Port site metastases after laparoscopic colorectal surgery for cure of malignancy. Br J Surg, 82:295-298.

[35] Fleshman JW, Nelson H, Peters WR, Kim HC, Larach S, Boorse RR, Ambroze W, Leggett P, Bleday R, Stryker S, Christenson B, Wexner S, Senagore A, Rattner D, Sutton J, Fine AP (1996). Early results of laparoscopic surgery for colorectal cancer. Retrospective analysis of 372 patient treated by Clinical Outcomes of Surgical Therapy (COST) Study Group. Dis Colon Rectum, 39(10 Suppl):S53-8.

[36] Colon Cancer Laparoscopic or Open Resection Study Group, Buunen M, Veldkamp R, Hop WC, Kuhry E, Jeekel J, Haglind E, Pahlman L, Cuesta MA, Msika S, Morino M, Lacy A, Bonjer HJ (2009). Survival after laparoscopic surgery versus open surgery for colon cancer: long-term outcome of a randomised clinical trial. Lancet Oncol, 10(1):44-52.

[37] Jacob BP, Salky B (2005). Laparoscopic colectomy for colon adenocarcinoma: an 11-year retrospective review with 5-year survival rates. Surg Endosc, 19(5):643-9.

[38] Shaligram A, Smith L, Pallati P, Simorov A, Meza J, Oleynikov D (2013). Can laparoscopy for colon resection reduce the need for discharge to skilled care facility? Surg Endosc. 27(11):4038-43 
[39] Tyler JA, Fox JP, Desai MM, Perry WB, Glasgow SC (2013). Outcomes and costs associated with robotic colectomy in the minimally invasive era. Dis Colon Rectum, 56(4):458-66. 